\title{
On a unique fellow and a good friend: Celebrating the life of Stefan Hesse and his contributions to rehabilitation robotics, 1960-2016
}

Hermano Igo Krebs Massachusetts Institute of Technology, Newman Laboratory for Biomechanics and Human Rehabilitation, Cambridge, MA, USA

Tel.: +1617253 8112; E-mail: hikrebs@mit.edu

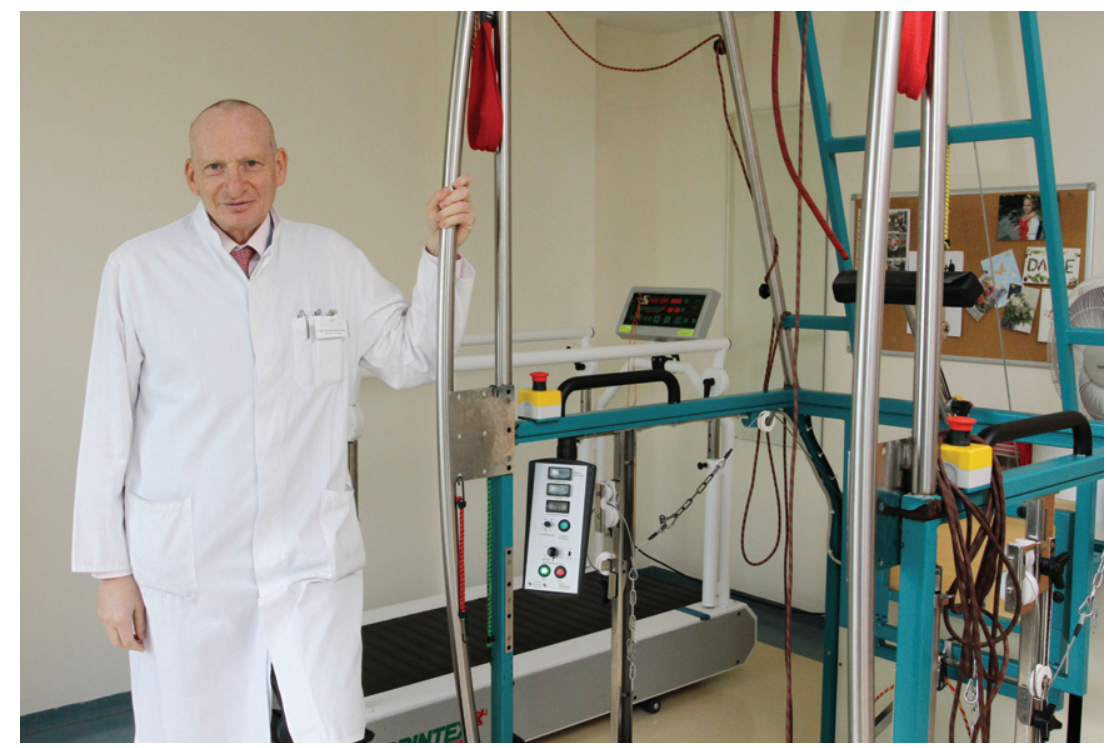

For my dear friend Stefan, you seemed to always be ahead of the curve; let your life serve as inspiration to those of us that for now stayed behind to carry on the work. Prost!

Five years ago I had the privilege of writing an editorial for this Journal presenting the state-of-theart in robotics. When Nathan Zasler, the Editor-inChief of Neurorehabilitation, asked me to wear the same "hat" again 5 years later, I was eager to include many of the same 2012 issue collaborators to allow the readership to compare "apples-to-apples" and to fully appreciate the march of progress we've seen in the field over the last 5 years. Regrettably, it is with tremendous sadness that I am not able to include a paper from my dear friend Dr. Stefan Hesse (PhD 1988, Neurology 1990, PMR 1996, Social Medicine 2004).

I first heard about Stefan Hesse in 1994. Fletcher McDowell, CEO and President of Burke Rehabilitation Hospital at the time, introduced me to this 
fun loving, optimistic fellow from the Black Forest. Stefan was a character. There was never a dull moment when he was around. His encyclopedic knowledge filled the room and his curiosity and energy were endless. In fact, there wasn't a language in Europe he could not speak or a historical fact that escaped him. I will never forget one of my visits to Berlin to see his clinic and robotic gym. Always a historian at heart, he brought me one Saturday to see the copy of the Flensburg Lion. My recollection is that it was a monument originally erected by the Danish as a memorial for the unknown soldier and to commemorate their victory over the Prussians. In the mid-1800s the Prussians won a rematch and took the Lion, which was returned in 1945 by the US Army; a copy remained in Berlin. While Stefan and I smirked at the German-Danish nobility and the confrontation among aristocracies, I can never forget how tears later rolled down his face as he pointed out the Wannsee Estate where the 1941 Wannsee Conference took place and he explained that this was where the Nazis planned for the "Final Jewish Solution."

That evening, we attended the Rose Ball, a fundraising event for stroke research and care. We were among celebrities and "rock-stars." I considered Stefan to be in that category. We sat next to Germany's Foreign minister in his impeccable black-tie outfit and many very tall women in their red-carpet gowns. Three different bands played during the fund-raising night and popular vocalists including Diane Warwick and Lionel Richie performed. Stefan and his lovely wife, Beata, danced "all night long." The oddity of the event is that Stefan and I were the only two not in black-tie and we arrived in a very old tiny blue miniFiat. No wonder none of the photographers at the red carpet came to snap a photo of us... That single Saturday was quintessential Stefan: knowledgeable, compassionate, strong, energetic, uber creative, and passionate. Indeed, super creative: he was one of the fathers/pioneers in the field of rehabilitation robotics with a keen entrepreneurial spirit always aiming to help his patients. And helping his patients was not just his profession, but his vocation. He loved his work!

Stefan's pioneering contributions were fundamental to the development of rehabilitation robotics. He helped advance the field, which has continued to mature since the early 90's with the development of more and more evidence. As of 2010 and again in 2016, an endorsement was received from the American Heart Association (AHA) for use of rehabilitation robotics in upper extremity post-stroke care (Miller et al., 2010; Winstein et al., 2016) and from the VA/DOD in their 2010 Guidelines. Stefan was leading the state-of-the-art in lower extremity rehabilitation robotics and, thanks to his leadership, I have no doubt that in the next revision of AHA guidelines, the AHA will be more generous and positive in conclusions about lower extremity robotics.

As I noted in 2012, I believe that the success of these kind of robotic tools rests in ceasing to think about the devices and starting to think about the rehabilitation processes. The goal is to rehabilitate a person following a neurological trauma, such as stroke or CP, and the devices are sophisticated tools which can enable and assist clinicians to facilitate this objective; they must be properly inserted and integrated into the rehabilitation process. We should not only augment the clinicians' repertoire of interventions, but do so while preserving the evidence that we've learned in terms of high intensity repetition, motor interference, generalization, consolidation, type and quality of feedback, etc. As I wrote in 2012, it is my firm belief that in order to insert robotics and thereby accelerate improvements in the effectiveness of the standard of care, we have also to change the way physical and occupational therapy, physical medicine, motor control, and rehabilitation engineering interact and are taught. In this rapidly advancing era of rehabilitation technology, all of us need specialized training in the fundamental principles of technology-assisted rehabilitation as they pertain to motor learning and motor control.

This issue includes a selected collection of papers that are intended to afford a vision of the march toward progress in the state-of-the-art in rehabilitation robotics. We can cluster these papers around upper extremity (Duret, Grosmaire, Friel, Cortes, Pizzamiglio) and lower extremity (Chang, Hirano, Tanabe, Lemaire, Michmizos); patient type including stroke (Grosmaire, Chang, Hirano), SCI (Cortes, Tanabe, Lemaire), or cerebral palsy (Friel and Michmizos); intent-of-use including rehabilitative (Grosmaire, Duret, Friel, Cortes, Pizzamiglio, Chang, Hirano, Michmizos) or assistive robotics (Tanabe and Lemaire).

Duret discussed the use of robotics for a broad spectrum of patients while Pizzamiglio concentrated on the importance of the concept of motor learning. Of the three papers on neurorecovery following a stroke involving the lower extremity, Chang investigates discrete training with an ankle robot in adults with stroke and Michmizos in children with cerebral 
palsy, while Hirano investigates rhythmic training with a knee robotic device in stroke. I might insert at this point that I have been advocating a working model that requires us to train discrete, rhythmic, and balance for a successful outcome in lower extremity. For the upper extremity, Grosmaire examines improvements in sub-acute stroke, Friel address adults with cerebral palsy, and Cortes looks at SCI. But we must acknowledge that beyond our best efforts to rehabilitate, we might also need assistive technology when our neurorehabilitation efforts hit a wall. Tanabe and Lemaire discuss very distinct types of exoskeleton robots.

I will conclude by reminding us that the mission of transitioning robot-assisted interventions into standard of care is crystal clear. The burden remains on us to make it happen and I hope this issue will teach us to learn where we were, are, and need to be in 5 years.

\section{References}

Miller, E. L., Murray, L., Richards, L., Zorowitz, R. D., Bakas, T., Clark, P., \& Billinger, S. A. (2010). Nursing American heart association council on cardiovascular, and council the stroke, "Comprehensive overview of nursing and interdisciplinary rehabilitation care of the stroke patient: A scientific statement from the American heart association," Stroke, 41, 2402-48.

The management of stroke rehabilitation working group. (2010). "VA/DOD clinical practice guideline for the management of 161 stroke rehabilitation," J Rehabil Res Dev, 47, 1-43.

Winstein, C. J., Stein, J., Arena, R., Bates, B., Cherney, L. R., Cramer, S., Deruyter, F., Eng, J. J., Fisher, B., Harvey, R. L., Lang, C. E., MacKay-Lyons, M., Ottenbacher, K. J., Pugh, S., Reeves, M. J., Richards, L. G., Stiers, W., Zorowitz, R. D. (2016). "Guidelines for adult stroke rehabilitation and recovery: A guideline for healthcare professionals from the American Heart Association/American Stroke Association," Stroke, 47(6), e98-e169. 